\title{
Tonal vocalizations in a noisy environment: an approach to their semi-automatic analysis and examples of its application
}

\author{
ROGER MUNDRY and CHRISTINA SOMMER \\ Institute of Biology, Department of Behavioural Biology, Free University of Berlin, \\ Haderslebener Str. 9, 12163 Berlin, Germany
}

Manuscript received on January 15, 2004; accepted for publication on February 5, 2004.

\begin{abstract}
Vocalizations with an emphasized fundamental are common in many species of animals. Such calls can presumably be sufficiently described by measures of their fundamental shape or 'contour'. Here we describe a software we developed to analyze such vocalizations semi-automatically. The software is particularly designed to cope with vocalizations recorded in a noisy environment. Some of the algorithms implemented (e.g. signal detection, contour detection, contour measurement, validation) and some preliminary applications dealing with calls of different species of birds are presented. Finally, we briefly discuss the possible significance of such vocalizations.
\end{abstract}

Key words: tonal vocalizations, contour measurement, software.

\section{INTRODUCTION}

Many animals face the problem of communicating acoustically over larger distances and/or in noisy environments (e.g. Lengagne et al. 1999). Under such circumstances, the acoustic quality of a signal is clearly altered between sender and receiver. These alterations include, for instance, degradation and superimposed environmental noise (e.g. Dabelsteen et al. 1993). However, animals communicating under such circumstances may need to extract information from these degraded signals. A possible strategy to cope with the problems associated with communication in a noisy environment is to use calls of a structure that can convey information also when being degraded and/or masked. An ideal candidate for such a call structure is a tonal vocalization with an emphasized and modulated fundamental frequency. Information may then be coded

Correspondence to: Roger Mundry

E-mail: rmundry@zedat.fu-berlin.de in the particular shape of the fundamental frequency. Interestingly, many species of birds and mammals utter these types of calls.

Researchers investigating vocal communication face the same problems as animal receivers. In fact, many recordings of vocalizations brought back from the field are of rather low quality, even when recording conditions were good (e.g. very small distance to the subject). For instance, Arabian Babblers Turdoides squamiceps often utter soft contact calls ('zips') while pecking on the ground (Zahavi and Zahavi 1997). Consequently, a large proportion of zips is heavily masked by noise of amplitude similar to that of the signal (Fig. 1). However, in the case of tonal vocalizations with an emphasized and modulated fundamental, it might be possible to analyze recordings of lower quality because the fundamental's contour or shape may still contain at least some of the information important for bioacoustic analyses of the species. 
We thus began to develop a software designed to measure acoustic properties also in low quality recordings of tonal calls. The software analyzes spectrograms derived from different common software packages. Basically, it involves three levels of analysis: signal detection, extraction of the fundamental's contour, and measuring the fundamental's contour. Some aspects of corresponding algorithms and concepts will be outlined in the following.

\section{SIGNAL DETECTION}

The signal detection algorithm uses thresholds that are dynamically adjusted for each file to be analyzed separately. It thus can be applied to a wide range of absolute amplitudes and signal-to-noise ratios. The software also allows for the detection of several signals within a file. To cope with low signal-tonoise ratios and at the same time prevent from errors, the software initially identifies those sections of the spectrogram that are most likely to include a signal. This is done by first determining the frequency distribution of the sum of amplitudes within time segments. Subsequently, a cut off point is determined from this distribution and each time segment with summed amplitude in excess of that cut off point is assumed to include part of the signal. Finally, only those sections are accepted as including signal that mainly consist of time points determined as part of the signal. From these sections the algorithm then 'moves' backward and forward and includes neighboring parts into the signal until a stopping criterion is met. Using the graphical interface it is possible to supervise and, if necessary, manually correct the results of the signal detection process by adding signals that have not been detected or removing noise that erroneously has been detected as a call. In addition, it is possible to manually adjust each signal's start and end, separately.

\section{CONTOUR DETECTION}

The contour detection uses one of two different algorithms depending on whether harmonics are present. If harmonics are absent or of only minor amplitude, contour detection is based on the determination of the frequency with the highest amplitude within each time segment. Subsequently, potential outliers are removed.

If harmonics are present, the contour detection algorithm combines the former method with linear auto-correlation analysis on the power-spectrum of a given time segment. The maximum of the autocorrelation function derived for a certain time segment is then assumed to equal the fundamental frequency in that time segment.

Like the signal detection, the contour detection algorithm initially is very conservative, and only considers those parts of the 'detected contour' that are most likely to represent the actual fundamental. Beginning at these 'cores', it then 'moves' back and forth to detect the fundamental's contour in the remaining signal. The algorithm usually runs a number of times, becoming increasingly permissive until a stopping criterion is met.

The graphical user interface displays the detected contours on the screen allowing an evaluation of whether the algorithm performed poorly or well. In addition, we implemented a variety of measures indicating the monotony and continuity of detected contours. Given the fact that many calls' fundamentals are of rather simple shape, these measures also allow for an evaluation of the success of the contour detection algorithm.

\section{MEASURING THE FUNDAMENTAL'S CONTOUR}

An issue that is interesting and problematic is how to measure the properties of a contour. In particular, in research about dolphin whistles there is some dispute about this topic (see e.g. Buck and Tyack 1993, Janik 1999, McCowan and Reiss 2001, BazúaDurán 2004). Suggesting a single solution is clearly beyond the scope of this contribution. In fact, the biological relevance of any chosen acoustical and statistical method to measure and compare calls can only be determined using carefully designed playback experiments conducted on subjects of the study species and under natural acoustic conditions. 
In the studies we have conducted so far using the developed software, we mainly applied an approach that could be termed 'parametric' (e.g. Schrader and Hammerschmidt 1997, Naguib et al. 2001). It consists of measuring the acoustic properties of contours in the time and frequency domains. The specific parameters implemented depend on the particular shape of the contours under study and partly also on the question investigated. Using contours that more or less resemble an inverted ' $U$ ' as an example (Figs. 1 and 2), some of the parameters we implemented will be described below.

We first take some basic measures like the frequency at the fundamental's start, maximum and end, the duration of the call, or time at maximum frequency. In addition, we determine the mean frequency of the fundamental as a whole, as well as for its two sections (before and after reaching maximum frequency). We apply this separation of calls into two sections for a variety of other measures as well. Furthermore, we determine slopes for the whole contour as well as for the two sections by simply connecting the respective endpoints. In addition, we measure slopes by means of linear regression analysis. Doing so allows for estimating the strength of the relation between time and frequency by determining $R^{2}$, the effect size of the regression.

To describe the shape of the fundamental in more detail, we use several approaches. First, we measure the frequency at several predefined timepoints, that is after the first, second and third quarter of each of the two sections of the vocalization. Second, we determine the location of 'bends' in the contour. We then measure how emphasized the bends are using the difference between regression slopes derived for the two sections before and after the bend. We are also investigating whether polynomial curve fitting could be an approach to measure such vocalizations. The idea is to find an equation of a form like:

$$
\begin{gathered}
f_{(x)=} c_{1} x^{6}+c_{2} x^{5}+c_{3} x^{4}+c_{4} x^{3}+c_{5} x^{2} \\
+c_{6} x+c_{7}
\end{gathered}
$$

where $f_{(x)}$ denotes the frequency of the contour at time segment $x$. If all contours to be analyzed are approximated using polynomials of the same order, then these contours could perhaps be sufficiently described by the coefficients $c_{1}, c_{2}$ etc. Although presumably quite 'unnatural', this approach may help to avoid the 'inflation of parameters' that commonly arises in acoustic analysis and consequently might be very useful for statistical analyses.

\section{EXEMPLARY APPLICATIONS}

We used the software to investigate the structure of long distance contact calls ('shouts') of Arabian Babblers, and analyzed the resulting parameters with regard to potential differences between subjects. Arabian Babblers are cooperatively breeding songbirds that live in the deserts of the Middle East. They live in groups that maintain a territory year round, and the groups most commonly consist of a pair of breeders and additional helpers that contribute to defending the territory, rearing the offspring, etc. (Zahavi and Zahavi 1997). Shouts are quite loud (audible for humans at distances up to more than 500 meters) and uttered during e.g. encounters between neighboring groups or when one bird lost its group mates. The calls usually consist of a series of similar elements, repeated at regular intervals (Fig. 2). Preliminary results indicate that the vocalizations from different birds clearly differed in the call's fundamental contours.

In a second study we investigated the structure of begging calls of Wilson's Storm Petrel Oceanites oceanicus nestlings. The particular question we asked was whether begging calls convey information about the nutritional need of chicks. A preliminary analysis of correlations between principal component factor scores of acoustic parameters of calls and residual chick weight indicated that aspects of the fundamentals' shape indeed correlated with the chicks' nutritional needs.

\section{CONCLUSION}

Together, these results indicate that contours of tonal vocalizations may convey information that 

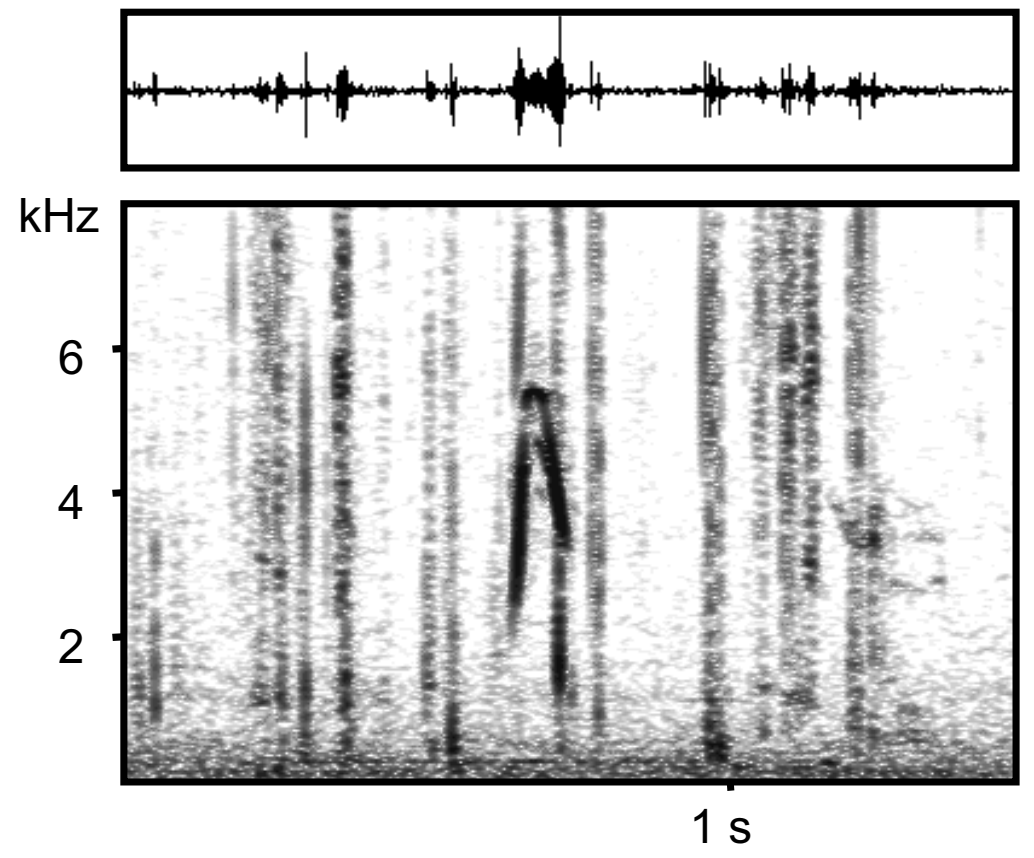

Fig. 1 - Contact call of an Arabian Babbler. Subjects commonly utter such calls during foraging. Note that the call is masked by noise (vertical lines) caused by subjects pecking on the ground.

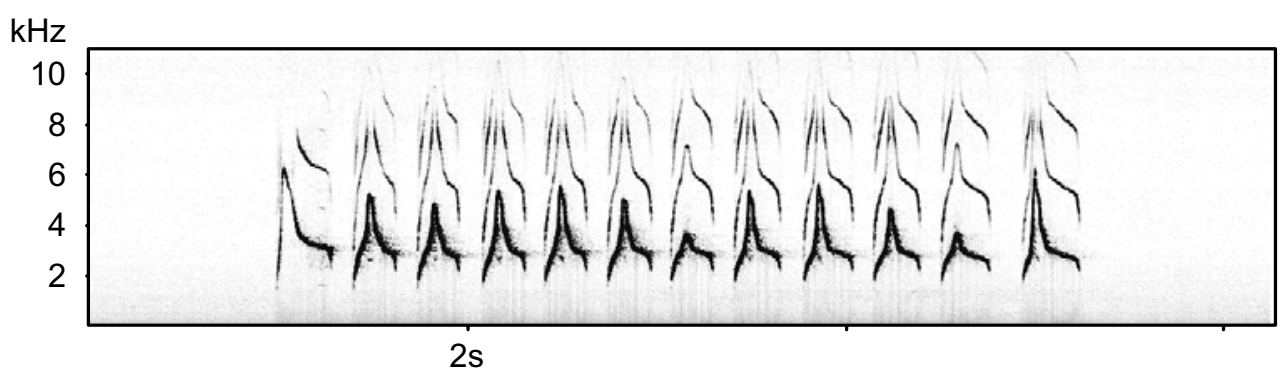

Fig. 2 - Far ranging contact call of an Arabian Babbler.

can be successfully extracted using the software presented and may also be decoded by the intended receivers. Because the contours of fundamentals are presumably less influenced by degradation, reverberation and environmental noise than are vocal cues, they can be measured reliably also from lower quality recordings. Focusing an acoustic analysis on the contours of fundamentals alone might thus be a reasonable means of elucidating aspects of signal meaning in animals.

\section{ACKNOWLEDGMENTS}

We wish to thank Petra Quillfeldt who provided data about and recordings of the Storm Petrels. Roni Ostreiher, Dietmar Todt, and Amotz Zahavi greatly supported our work with the Babblers. Barbara Diederich and Kurt Hammerschmidt contributed to the initiation of software development. The program described is available free of charge to anyone interested. 


\section{RESUMO}

Vocalizações com uma freqüência fundamental dominante são comuns em muitas espécies de animais. Presumivelmente tais sons podem ser adequadamente descritos pelas medições da forma ou "contorno" de sua fundamental. Descrevemos aqui um programa computacional que desenvolvemos para analisar essas vocalizações de maneira semi-automática. O programa é projetado especialmente para tratar das vocalizações registradas em ambiente ruidoso. Alguns dos algoritmos implementados (por ex. detecção de sinal, detecção de contorno, medição de contorno, validação) e algumas aplicações preliminares tratando dos gritos de diversas espécies de aves são apresentados. Finalmente, discutimos brevemente o possível significado dessas vocalizações.

Palavras-chave: vocalizações tonais, medições de contorno, programa computacional.

\section{REFERENCES}

BAZÚA-Durán C. 2004. Differences in the whistle characteristics and repertoire of Bottlenose and Spinner Dolphins. An Acad Bras Cienc 76: 386-392.

BuCK JR AND TYACK PL. 1993. A quantitative measure of similarity for Tursiops truncatus signature whistles. J Acoust Soc Am 94: 2497-2506.

Dabelsteen T, Larsen ON and Pedersen SB. 1993. Habitat-induced degradation of sound signals: quantifying the effects of communication sounds and bird location on blur ratio, excess attenuation, and signalto-noise ratio in Blackbird song. J Acoust Soc Am 93: 2206-2220.
JANIK VM. 1999. Pitfalls in the categorization of behaviour: a comparison of dolphin whistle classification methods. Anim Behav 57: 133-143.

Lengagne T, Aubin T, Lauga J and Jouventin P. 1999. How do King Penguins (Aptenodytes patagonicus) apply the mathematical theory of information to communicate in windy conditions? Proc Royal Soc London, B 266: 1623-1628.

McCowan B AND ReIss D. 2001. The fallacy of 'signature whistles' in Bottlenose Dolphins: a comparative perspective of 'signature information' in animal vocalizations. Anim Behav 62: 1151-1162.

Naguib M, Hammerschmidt K And Wirth J. 2001. Microgeographic variation, habitat effects and individual signature cues in calls of Chiffchaffs Phylloscopus collybita canarensis. Ethology 107: 341-355.

Schrader L and Hammerschmidt K. 1997. Computeraided analysis of acoustic parameters in animal vocalizations: a multi-parametric approach. Bioacoustics 7: 247-265.

Zahavi A and Zahavi A. 1997. The handicap principle: a missing piece of Darwin's puzzle. Oxford: Oxford University Press. 